\title{
Analysis and settlement evaluation of an end- bearing granular pile with non-linear deformation modulus
}

https://doi.org/10.2478/sgem-2018-0022

received April 16, 2018; accepted June 18, 2018.

Abstract: Ground improvement with granular piles increases the load-carrying capacity, reduces the settlement of foundations built on the reinforced ground and is also a good alternative to concrete pile. Granular piles or stone columns are composed of granular material, such as crushed stone or coarse dense sand. An analytical approach based on the continuum approach is presented for the non-linear behaviour of the granular pile. The formulation for pile element displacement is done considering the non-homogeneity of the granular pile as it reflects the true behaviour and also accounts for the changes in the state of the granular pile due to installation, stiffening and improvement effects. The present study shows that the settlement influence factor for an endbearing granular pile decreases with increase in the relative stiffness of the bearing stratum. The settlement influence factor decreases with increase in linear and non-linear non-homogeneity parameters for all values of relative length. For a shorter pile, the rate of decrease of the settlement influence factor is greater in comparison to that for a longer pile. Shear stress at the soil-granular pile interface reduces in the upper compressible portion of the granular pile and increases in the lower stiffer portion of the granular pile due to the non-homogeneity of an endbearing granular pile.

Keywords: end-bearing granular pile; relative stiffness of bearing stratum; relative stiffness of granular pile; deformation modulus; settlement influence factor.

\footnotetext{
*Corresponding author: Jitendra Kumar Sharma, Rajasthan Technical University, Kota, Rajasthan, E-mail: jksharma@rtu.ac.in Pooja Gupta: Maharishi Arvind International Institute of Technology, Kota, Rajasthan
}

\section{Abbreviations}

$\mathrm{GP}=$ granular pile; $L=$ length of GP; $D=$ diameter of GP; $P=$ load on GP; $E_{\mathrm{gp}}=$ deformation modulus of the material of the GP; $z^{*}(=z / L)$ normalised depth of GP; $E_{s}, v_{s=}$ deformation modulus and Poisson's ratio of soil; $K_{\mathrm{gp0}}=$ relative stiffness of $\mathrm{GP}=\left(\mathrm{E}_{\mathrm{gp0}} / \mathrm{E}_{\mathrm{s}}\right) ; p_{\mathrm{b}}=$ pile base pressure; $\alpha$ and $\delta=$ degrees of non-homogeneity of GP; $I_{\mathrm{sp}}$ = settlement influence factors; $E_{\mathrm{b}} / E_{\mathrm{s}}=$ relative stiffness of the bearing stratum; $\tau^{\star}=$ normalised shear stresses of GP $=(\tau /(P / \pi \mathrm{d} L)) ; n=$ total number of elements of GP; $E_{\mathrm{gp}}=$ stress-independent deformation modulus or deformation modulus at the top of the GP; $v_{\mathrm{b}}=$ Poisson's ratio for the base of the GP.

\section{Introduction}

A number of analyses are available for the estimation of the settlement of piles and pile groups based on the continuum approach [1-3], but most of them are for homogeneous piles and soil masses. The reasons for the non-homogeneity of granular piles have been discussed by Madhav et al. [4] and Gupta and Sharma [5].

Analysis of a non-homogeneous floating granular pile was presented by Madhav et al. [4], considering the linear variation of the deformation modulus with the length of the granular pile. Gupta and Sharma [5] analysed non-homogeneous floating granular piles considering the non-linear variation of the deformation modulus with the length of the pile. Alamgir et al. [6] proposed the deformation behaviour of a soft ground reinforced with stone columns installed in a group, using a simple analytical approach. Madhav et al. [7] discussed about the settlement and load distribution in a granular piled raft. Zhang et al. [8] presented the settlement calculation of a foundation of composites reinforced with stone column. Indraratna et al. [9] presented a numerical model (finite difference method) to analyse the response of stone column-reinforced soft soil under embankment loading. 
Randolph and Wroth [10] presented an analysis of the deformation of vertically loaded piles in linear elastic soil. The application of this method in pile design was discussed, and design curves were sketched for different geometries in two typical soft clay deposits. Eldho et al. [11] presented a case study on ground improvement using stone columns and prefabricated vertical drains (PVDs). Hayashi et al. [12] described the field performance of PVDs used in combination with reinforced embankment on peaty ground. Cecilia and Serge [13] presented the case studies of stone column improvement in a seismic area. An inventory of the observed performance of such systems in seismic conditions and recent applications of stone columns combined with pile foundations were presented. Andreou and Papadopoulos [14] studied the factors affecting the settlement estimation of stone column-reinforced ground. Etezad et al. [15] presented an analytical model to predict the bearing capacity of soft soil reinforced with stone columns under rigid raft foundation subject to general shear failure mechanism. The model utilises the limit-equilibrium method and the concept of composite properties of reinforced soil.

Construction of granular piles is done in stages, with granular material placed in lifts in the hole and then compacted. Increase of in situ confining stresses from the surrounding soil with depth may lead to different degrees of compaction and unit weight with depth, leading to nonhomogeneity of granular pile in terms of its deformation modulus, although the energy input for compaction at each stage of construction of the granular pile is constant. Depending on the design requirements, granular piles are normally constructed to penetrate the soft layer fully, if the latter is not very thick (e.g. less than 12.0-15.0 m) and ends on a bearing stratum. For normal-sized granular piles, smaller values of $L / d$ represent shorter piles, while larger values correspond to longer piles.

\section{Problem definition and method of analysis}

The basic assumptions in the analysis are as follows:

1. The base of the stone column/granular pile is assumed to be smooth and rigid, across which the load is uniformly distributed [4].

2. The disturbance effects in the in situ soil due to the installation of granular piles are ignored and considered as homogeneous.

3. The installation effect is considered in terms of the non-linear deformation modulus of the granular pile.
4. The settlement of the granular pile depends on its deformation modulus and geometry, besides the magnitude of the load. Based on various previous studies, the consideration of non-homogeneity of the granular pile is appropriate and close to the in situ behaviour. The non-homogeneity of a granular pile is considered in terms of its deformation modulus with non-linear variation.

The essential steps of the analysis are described in the following sections.

\subsection{Soil displacements}

The granular pile is discretised into $n$ cylindrical elements acted upon by shear stresses $\tau$, with the base having a uniform pressure $p_{\mathrm{b}}$. The granular pile base is assumed to be smooth, across which the load is uniformly distributed. The soil displacements of the nodes on the granular pile periphery and the centre of each element are evaluated based on the influence of the elemental shear stresses. Thus, the soil displacement equation for a granular pile resting on a stiff bearing stratum is as follows:

$$
\left\{\rho^{s}\right\}=\left\{\frac{S^{s}}{d}\right\}=\left[\left[I^{s p}\right]-\kappa\left[I^{\text {spim }}\right]\right]\left\{\frac{\tau}{E_{S}}\right\},
$$

where $\left\{S^{s}\right\}$ and $\left\{\rho^{s}\right\}$ are the soil displacement and the normalised soil displacement vectors, respectively; $\left\{\rho^{s}\right\}$ is of size $n$ for end-bearing granular piles; $\left\{\tau / E_{s}\right\}$ is the column vector of size $n$ of shaft stresses only, excluding the base pressure. To account for the influence of the bearing stratum, the mirror image approximation [1] is used. The influence of the mirror image elements is taken as $\kappa$ times the influence of shear stresses on the real elements in the negative direction, where $\mathrm{k}$ is a non-dimensional parameter that accounts for the compressibility of the base and lies between zero and one for a floating granular pile and a granular pile resting on a rigid stratum, respectively (Fig. 1 ). $\left[I^{\mathrm{sp}}\right]$ is a square matrix of the soil displacement influence coefficients of size $n$ for an end-bearing granular pile. [ $\left.{ }^{\text {spim }}\right]$ is a square matrix of the soil displacement influence coefficients due to the image elements of size $n$.

\subsection{Pile displacements}

Settlement of the base of a granular pile resting on a bearing stratum of finite compressibility is approximated 
GL

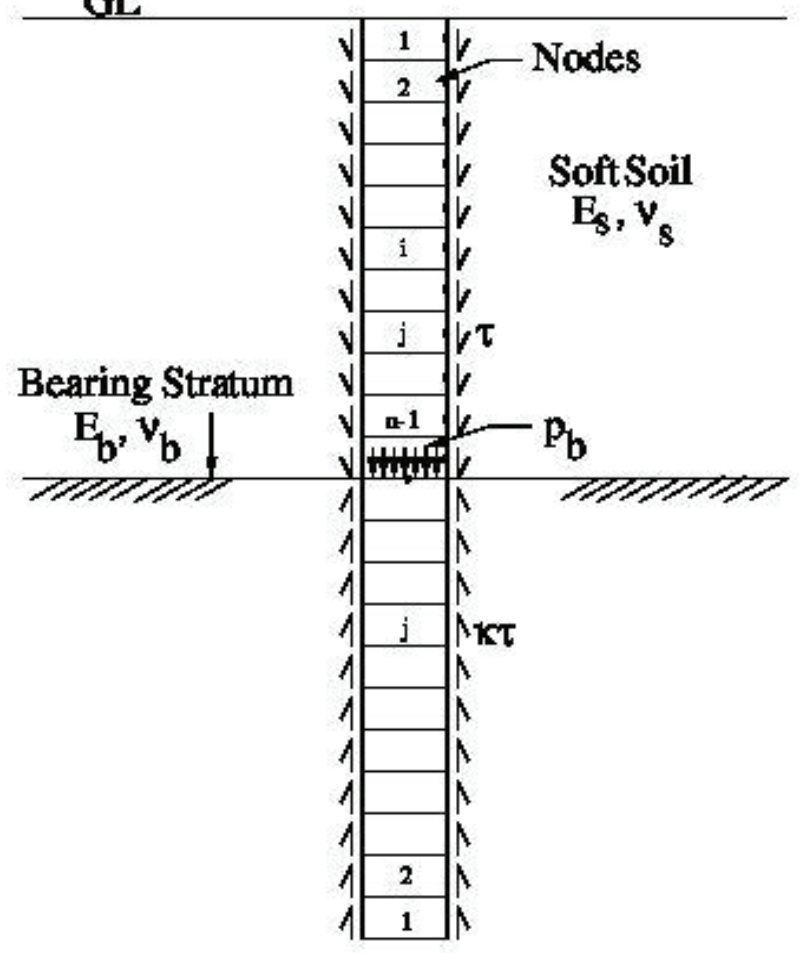

Figure 1: Mirror image technique for a granular pile resting on bearing stratum.

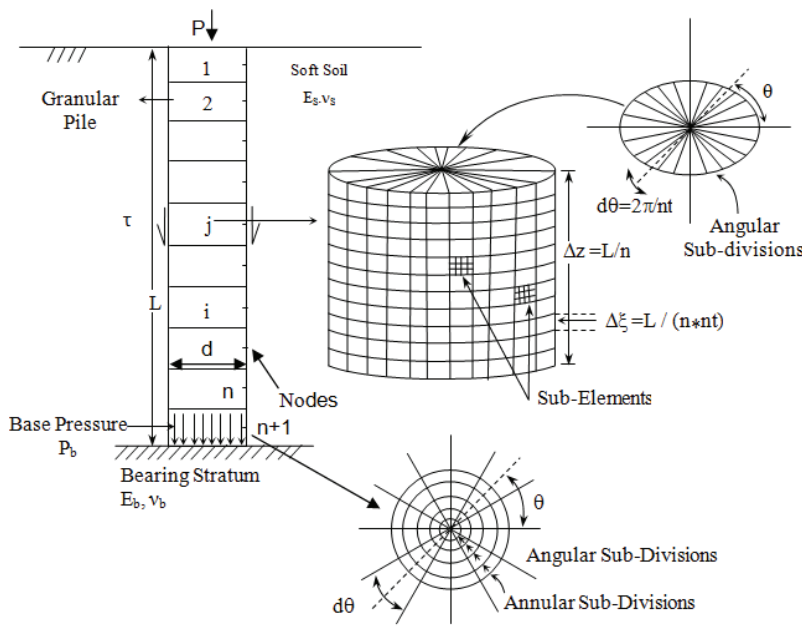

Figure 2: Pile discretisation scheme.

by the equation for the displacement of a rigid circular disc on a semi-infinite mass as shown in Eq. 2:

$$
\rho_{b}^{p}=\frac{S_{b}^{p}}{d}=\frac{p_{b}\left(1-v_{b}^{2}\right) \pi / 4}{E_{b}} .
$$

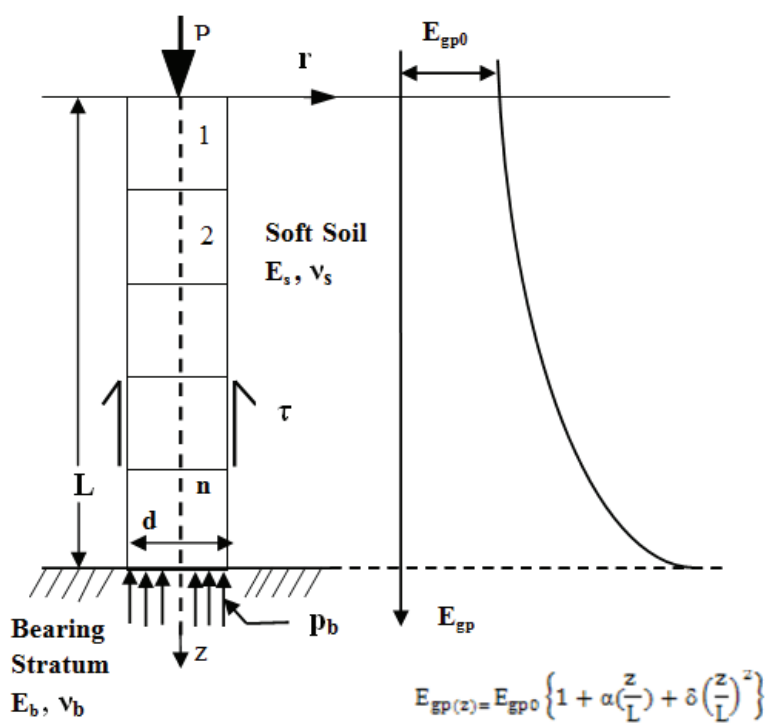

(a)

(b)

Figure 3: (a) End-bearing pile; (b) variation of modulus of deformation with depth.

From the equilibrium equation, the base pressure is expressed in terms of shear stresses as follows:

$$
p_{b}=\frac{P}{\pi d^{2} / 4}-\frac{4(L / d)}{n} \sum_{j=1}^{j=n} \tau_{j}
$$

Thus, the settlement of the base can be expressed in terms of the applied load and the mobilised shear stresses, using Eqs. (2) and (3), as follows:

$$
\rho_{b}=\left[\frac{P}{E_{S} \pi d^{2} / 4}-\frac{4(L / d)}{n} \sum_{j=1}^{j=n} \frac{j j}{E_{S}}\right] \times \frac{\pi\left(1-v_{b}^{2}\right)}{4\left(E_{b} / E_{S}\right)} .
$$

Settlement of the $n$th element is estimated as the settlement of the base plus the settlement of the element due to the axial stress acting on it, as shown in Eq. (5):

$$
\rho_{n}^{p}=\rho_{b}^{p}+\frac{\sigma_{n}(\Delta z / 2 d)}{E_{g p}}
$$

where $\sigma_{n} / E_{g p}$ is theaxial strain of the $n^{\text {th }}$ element and $\Delta z$ is the element length. As the pile is compressible, the settlement of each node is different: it is the least for the base node and gradually increases for the upward nodes, with the maximum at the top of the pile. Thus, the settlement of any node is calculated as the settlement of the base plus 
the settlement of all the elements downwards to the node and half of the settlement of the element related with the node under consideration. Settlement of any element $i$ is estimated as the settlement of the $(i+1)$ th element plus the settlement of the element due to the axial stress acting on it. Thus, the settlement of any element $i$ of the granular pile is represented as follows:

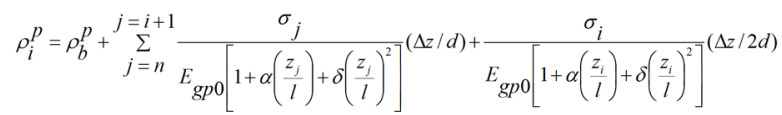

This set of displacement equations is expressed in matrix form as shown in Eq. (7):

$$
\left\{\rho^{p}\right\}=\rho_{b}\{1\}+\left[\Delta_{1}\right]\left\{\frac{\sigma}{E_{S}}\right\}
$$

where $\left[\Delta_{1}\right]$ is the upper triangular matrix as per Eq. (6), incorporating the non-homogeneity of the granular pile. Furthermore, using Eq. (4) for replacing the base displacement, Eq. (7) can be written as follows:

$\left\{\rho^{p}\right\}=\frac{P\left(1-v_{b}^{2}\right)}{\left(E_{b} / E_{S}\right) d^{2} E_{S}}\{1\}-\frac{\pi(L / d)\left(1-v_{b}^{2}\right)}{n\left(E_{b} / E_{S}\right)}[1]\left\{\frac{\tau}{E_{S}}\right\}+\left[\Delta_{1}\right]\left\{\frac{\sigma}{E_{S}}\right\}$,

where $\{1\}$ and [1] are, respectively, the column vector and the square matrix of size $n$ in which each term is unity. The shaft shear stresses and axial stresses of the elements are related (based on equilibrium relationship) as follows:

$\sigma_{i}=\frac{P}{\left(\pi d^{2} / 4\right)}-\sum_{j=1}^{j=i-14 \tau_{j} L} \frac{2 \tau_{i} L}{n d}$

The equation may be written in the matrix form for elements $i=1 . . . n$ as follows:

$$
\left\{\frac{\sigma}{E_{S}}\right\}=\frac{P}{\left(\pi d^{2} / 4\right) E_{S}}-\frac{4(L / d)}{n}\left[\Delta_{2}\right]\left\{\frac{\tau}{E_{S}}\right\},
$$

where $\left[\Delta_{2}\right]$ is the lower triangular matrix of size $n$ in which the diagonal and off-diagonal terms are 0.5 and 1.0, respectively. Using the relationship between axial stresses and shaft shear stresses (Eq. 10), the final form of the displacement equations for elements $i=1 . . . n$ in terms of the shaft shear stresses shown in Eq. (8) is as follows:

$$
\{\rho p\}=\{Y\}+[\Delta]\left\{\frac{\tau}{E_{S}}\right\}
$$

where

$$
\begin{aligned}
& \{Y\}=\frac{P\left(1-v_{b}^{2}\right)}{\left(E_{b} / E_{S}\right) d^{2} E_{S}}\{1\}+\frac{P}{\left(\pi d^{2} / 4\right) E_{S}}\left[\Delta_{1}\right]\{1\} \\
& {[\Delta]=-\frac{4(L / d)}{n}\left[\Delta_{1}\right]\left[\Delta_{2}\right]-\frac{\pi(L / d)\left(1-v_{b}^{2}\right)}{n\left(E_{b} / E_{S}\right)}[1]}
\end{aligned}
$$

\subsection{Compatibility of displacements}

Satisfying the compatibility of vertical displacements of the granular pile resting on a stiff bearing stratum [1] and the soil, the solutions are obtained in terms of the interface shear stresses and base pressure.

$$
\left\{\rho^{s}\right\}=\left\{\rho^{p}\right\} .
$$

For a granular pile resting on a stiff bearing stratum, satisfying Eqs. (1) and (11), the interface shear stresses are as follows:

$$
\left\{\frac{\tau}{E_{S}}\right\}=\left[\left[I^{s p}\right]-\kappa\left[I^{s p i m}\right]-[\Delta]\right]^{-1}\{Y\}
$$

For estimation of $\kappa$, an iterative technique suggested by Poulos and Mattes [2] is used. With an initial chosen value of $\kappa$, Eqs. (3) and (14) are solved to estimate the $n$ unknown shear stresses, $\tau$, and base pressure, $p_{\mathrm{b}}$. Having obtained the solution for the chosen value of $\kappa$, a closer estimate of the correct value of $\kappa$ is obtained by considering the compatibility between the displacements of the soil and the bearing stratum at the pile tip. The soil displacement at the pile tip is represented as follows:

$$
\rho_{b}^{S}=\frac{S_{b}^{S}}{d}=\left\{I_{j}^{s b}-\kappa I_{j}^{s b i m}\right\}\left\{\frac{\tau}{E_{S}}\right\}=\frac{\sum_{j=1}^{j=n}\left(I_{j}^{s b}-\kappa I_{j}^{s b i m}\right) \tau_{j}}{E_{S}} .
$$

$I_{j}^{s b}$ and $I_{j}^{s b i m}$ are the displacement influence coefficients for the tip due to shear stresses on the real and imaginary elements of $j$, respectively. However, due to the symmetry $I_{j}^{s b}=I_{j}^{s b i m}$, equating the soil displacement at the pile tip to the displacement of the base due to the base stress $p_{\mathrm{b}}$ (Eq. 2), the new value of the parameter $\kappa$ is obtained as follows:

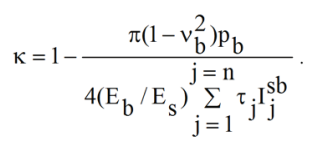


Table 1: Validation of results with those of Mattes and Poulos [1] and Poulos and Mattes [2].

\begin{tabular}{lll}
\hline Parameters & $\begin{array}{l}\text { Settlement influence } \\
\text { factor }\left(I_{\mathrm{sp}}\right)\end{array}$ & References \\
\hline (a) End-bearing pile & 0.0776 & {$[1,2]$} \\
$L / d=10, K_{\mathrm{gp} 0}=100$, & & \\
$v_{\mathrm{s}}=0.5, E_{\mathrm{b}} / E_{\mathrm{s}}=100$ & & \\
(b) End-bearing pile & 0.07756 & \\
$L / d=10, K_{\mathrm{gp} 0}=100$, & & \\
$v_{\mathrm{s}}=0.5, E_{\mathrm{b}} / E_{\mathrm{s}}=100$ & & \\
\hline
\end{tabular}

Eq. (14) is solved iteratively using the new value of $\kappa$, and the process is repeated until the required convergence is obtained for the value of $\kappa$.

The normalised top settlement of a single nonhomogeneous end-bearing granular pile is obtained as follows:

$$
\rho_{\text {top }}=\frac{S_{\text {top }}}{d}=\frac{P}{\frac{\pi}{4} E_{s} d^{2}} I_{s p}
$$

The top settlement of a single non-homogeneous endbearing granular pile is obtained as follows:

$$
S_{\text {top }}=\frac{P}{\frac{\pi}{4} E_{S} d} I_{s p}
$$

where $I_{\mathrm{sp}}$ is the settlement influence factor, which depends on various parameters related to the granular pile and the soil. The overall response of the non-homogeneous granular pile is evaluated in terms of the settlement influence factor, normalised shear stress and axial load distributions along the granular pile-soil interface, as well as the percentage of load transferred to the base. Parameters affecting the overall response are (i) length-to-diameter ratio of the granular pile $(L / d)$, (ii) the relative stiffness parameter, $K_{\mathrm{gp} 0}=\left(E_{\mathrm{gp} 0} / E_{\mathrm{s}}\right)$, (iii) the relative stiffness of the bearing stratum $E_{\mathrm{b}} / E_{\mathrm{s}}$, (iv) the degree of non-homogeneity of granular pile, $\alpha$ and $\delta$, and the (v) Poisson's ratios of the soft soil $\left(v_{\mathrm{s}}\right)$ and the base $\left(v_{\mathrm{b}}\right)$. Results are also evaluated in terms of variation of normalised axial load $P_{z}{ }^{*}\left(=P_{z} / P\right)$.The axial load of pile $P_{z}$ up to any element $m$ from the top of granular pile is defined as in Eq. (19):
$\left(\mathrm{P}_{\mathrm{z}}\right)_{\mathrm{m}}=\mathrm{P}-\sum_{\mathrm{i}=1}^{\mathrm{m}-1} \tau_{\mathrm{i}} \frac{\pi \mathrm{dL}}{\mathrm{n}}-\frac{\tau_{\mathrm{m}}}{2} \frac{\pi \mathrm{dL}}{\mathrm{n}}$.

\section{Results and discussion}

Results are obtained for the following ranges of nondimensional parameters: $K_{\mathrm{gp} 0}=E_{\mathrm{gp} 0} / E_{\mathrm{s}}=10-1000, E_{\mathrm{b}} /$ $E_{\mathrm{s}}=1-1000, \alpha=0-4, \delta=0-4, v_{\mathrm{s}}=0.3-0.5, v_{\mathrm{b}}=0.3-0.5$ and $L /$ $d=10-40$. The results obtained in this analysis have been validated with those of Mattes and Poulos [1], for single compressible end-bearing homogeneous piles $(\alpha=0)$. The agreement has been very close as shown in Table 1.

The variation of the settlement influence factor $I_{\mathrm{sp}}$ with the relative granular pile-soil stiffness parameter, $K_{\mathrm{gp} 0}$, for the relative length of a floating granular pile $L / d$ $=10$ and the relative stiffness of bearing stratum $E_{\mathrm{b}} / E_{\mathrm{s}}=10$ is depicted in Fig. 4, showing the effect of the degree of non-linear non-homogeneity, $\delta$. With the increase of the relative stiffness parameter, $K_{\mathrm{gp} \text {, }}$, the settlement influence factor $I_{\mathrm{sp}}$ decreases for all values of the non-linear nonhomogeneity parameter $\delta$. The settlement influence factor decreases with an increase of the degree of nonhomogeneity, $\delta$, due to variation in the deformation modulus of the granular pile. The non-homogeneity parameter increases the deformation modulus with depth. This leads to a rearrangement of the interfacial shaft stresses along the pile length. The effect of the degree of non-homogeneity is pronounced in the range of $K_{\mathrm{gp} 0}=10-150$. The settlement influence factors for $K_{\mathrm{gp} 0}=$ $50, E_{\mathrm{b}} / E_{\mathrm{s}}=10$ and $\delta=0,1,2,3$ and 4 are 0.137, 0.129, 0.122, 0.117 and 0.113 , respectively. The percentage decrements in the settlement influence factors in comparison to that of the homogeneous end-bearing granular pile are 5.83, 10.9, 14.6 and 17.51 for $\delta=1,2,3$ and 4, respectively. The effect of non-homogeneity on the settlement influence factor decreases with increasing values of $K_{\mathrm{gpo}}$ in the range of $700-1000$.

Figure 5 shows the variation of the settlement influence factor $I_{\mathrm{sp}}$ with the relative granular pile-soil stiffness parameter, $K_{\mathrm{gp} p}$, the relative stiffness of the bearing stratum $E_{\mathrm{b}} / E_{\mathrm{s}}=100$, for a relative length of the floating granular pile $L / d=10$, along with the effect of the degree of non-homogeneity, $\delta$. With the increase of the relative stiffness parameter, $K_{\mathrm{gp}}$, the settlement influence factors $I_{\mathrm{sp}}$ decrease for all values of the nonhomogeneity parameter $\delta$. The settlement influence factor decreases with increase in the degree of nonhomogeneity, $\delta$. As expected, the settlement influence factors for a granular pile resting on a relatively stiff 
$\mathrm{L} / \mathrm{d}=10, \mathrm{~K}_{\mathrm{g} p 0}=10$ to $1000, \mathrm{v}_{\mathrm{s}}=0.5, \mathrm{v}_{\mathrm{b}}=0.5, \mathrm{E}_{\mathrm{b}} / \mathrm{E}_{\mathrm{s}}=10, \boldsymbol{a}^{\prime}=0, \delta=0$ to 4

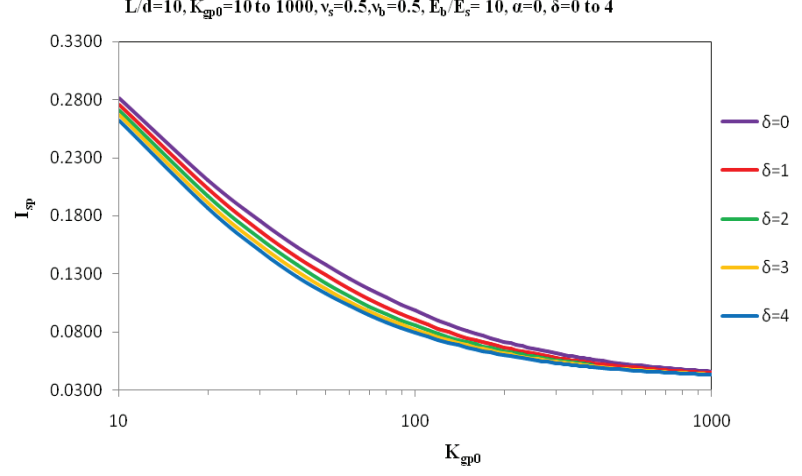

Figure 4: Variation of the settlement influence factor $l_{\mathrm{sp}}$, with the relative stiffness, $K_{\mathrm{gpo}}$, for an end-bearing granular pile: effect of the non-linear non-homogeneity parameter, $\delta\left(E_{\mathrm{b}} / E_{\mathrm{s}}=10\right)$.

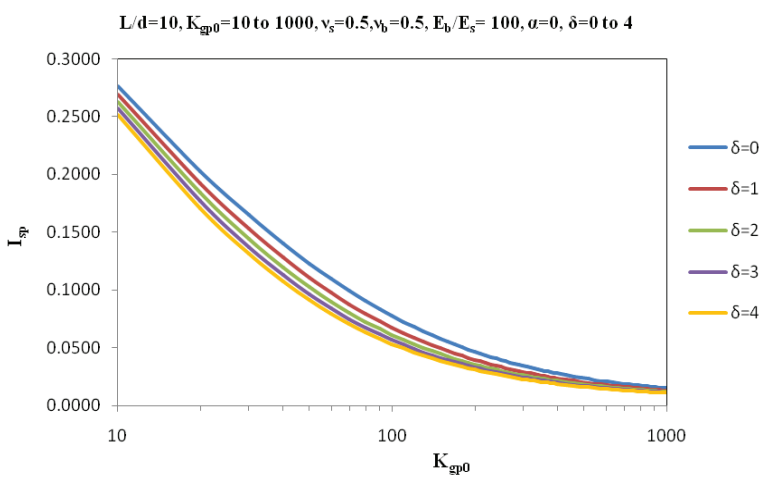

Figure 5: Variation of the settlement influence factor $l_{\mathrm{sp}}$, with relative stiffness, $K_{\mathrm{gp} 0}$, for end-bearing granular pile: effect of the non-linear non-homogeneity parameter, $\delta\left(\alpha=0, L / d=10, E_{\mathrm{b}} / E_{\mathrm{s}}=100\right)$.

stratum, $E_{\mathrm{b}} / E_{\mathrm{s}}=100$, are less compared to those resting for a granular pile on a stratum of stiffness, $E_{\mathrm{b}} / E_{\mathrm{s}}=10$ for all values of the non-homogeneity parameter, $\delta$, and relative stiffness parameter, $K_{\mathrm{gp} 0}$. The stiffer the bearing stratum $\left(E_{\mathrm{b}} / E_{\mathrm{s}}=100\right)$, the more load is transferred to the base and the effect of the non-homogeneity parameter, $\delta$, on the settlement influence factor, decreases. The settlement influence factors for $K_{\mathrm{gp} 0}=50, E_{\mathrm{b}} / E_{\mathrm{s}}=100$ and for $\delta=0,1,2,3$ and 4 are 0.123, 0.110, 0.102, 0.096 and 0.0909 , respectively. The percentage decrements in the settlement influence factors in comparison to that of a homogeneous end-bearing granular pile are 10.6, 17.07, 21.9 and 26.09 for $\delta=1,2,3$ and 4, respectively. The effect of non-homogeneity on the settlement influence factor decreases with increasing values of $K_{\mathrm{gp}}$.

Figure 6 shows the variation of the settlement influence factor $I_{\mathrm{sp}}$ with the relative granular pile-soil stiffness parameter, $K_{\mathrm{gp} 0}$, with the effect of the degree of non-

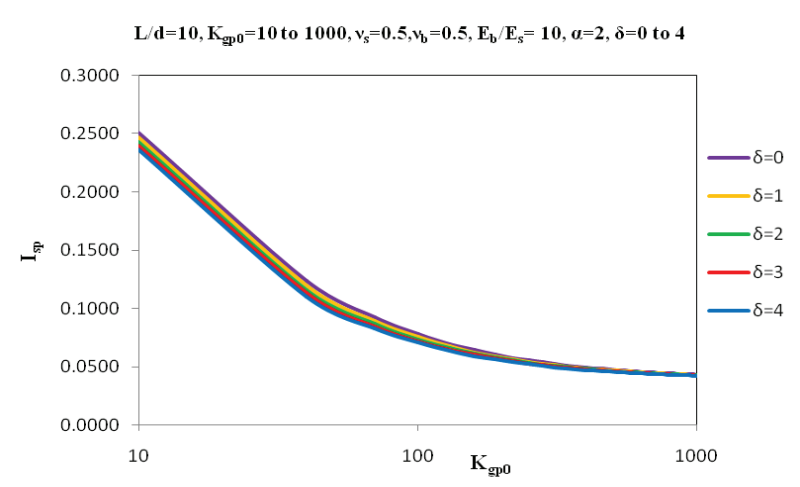

Figure 6: Variation of the settlement influence factor $l_{\mathrm{sp}}$, with the relative stiffness, $K_{\mathrm{gp} 0}$, for end-bearing granular pile: effect of the non-linear non-homogeneity parameter, $\delta\left(\alpha=2, L / d=10, E_{\mathrm{b}} / E_{\mathrm{s}}=10\right)$.

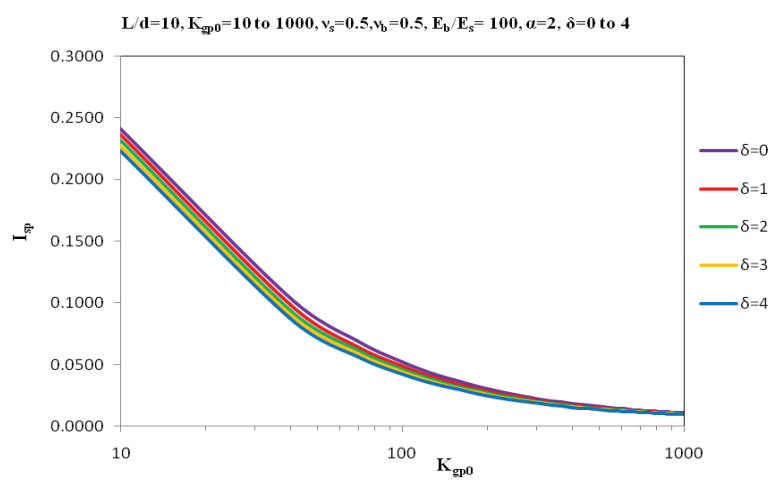

Figure 7: Variation of the settlement influence factor $l_{\text {sp }}$ with the relative stiffness, $K_{\mathrm{gpo}}$, for end-bearing granular pile: effect of the non-homogeneity parameter, $\delta\left(\alpha=2, L / d=10, E_{\mathrm{b}} / E_{\mathrm{s}}=100\right)$.

linear non-homogeneity, $\delta$, and linear non-homogeneity parameter of non-homogeneous end-bearing granular pile $(\alpha=2)$. With increase in the relative stiffness parameter, $K_{\mathrm{gp} 0}$, and the linear non-homogeneity parameter, $\alpha=0$ (Fig. 5) to $\alpha=2$ (Fig. 6), the settlement influence factor $I_{\mathrm{sp}}$ decreases for all values of the non-homogeneity parameter $\delta$. In the range of $K_{\mathrm{gpo}}=700-1000$, the effect of the degree of nonlinear non-homogeneity, $\delta$, reduces and the settlement influence factor becomes almost the same for all values of the degree of non-homogeneity.

Figure 7 shows the variation of the settlement influence factor $I_{\mathrm{sp}}$ with the relative granular pile-soil stiffness parameter, $K_{\mathrm{gp} 0}$, with the effect of the degree of non-linear non-homogeneity, $\delta$, and the linear nonhomogeneity parameter of a non-homogeneous pile $(\alpha=2)$. The settlement influence factors for a granular pile resting on a relatively stiff stratum, $E_{\mathrm{b}} / E_{\mathrm{s}}=100(\alpha=2)$, are lower compared to those for a pile resting on a stratum 


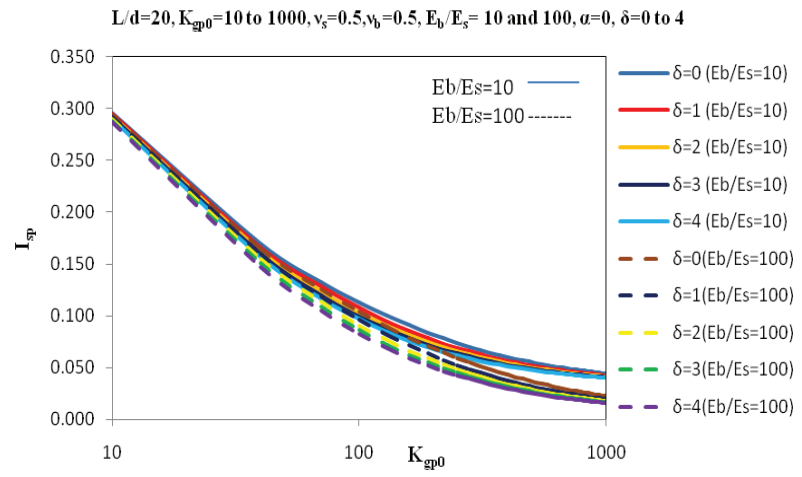

Figure 8: Variation of the settlement influence factor $l_{\mathrm{sp}}$, with the relative stiffness, $K_{\mathrm{gpo}}$, for an end-bearing granular pile: effect of the non-linear non-homogeneity parameter, $\delta\left(\alpha=0, L / d=20, E_{\mathrm{b}} / E_{\mathrm{s}}=10\right.$ and 100).

of stiffness, $E_{\mathrm{b}} / E_{\mathrm{s}}=10(\alpha=2)$ (Fig. 7), for all values of the non-homogeneity parameter, $\delta$, and the relative stiffness parameter, $K_{\mathrm{gp} 0}$.

Figure 8 shows the variation of the settlement influence factor $I_{\mathrm{sp}}$ with the relative stiffness parameter, $K_{\mathrm{gp} 0}$, for a longer granular pile $(L / d=20)$ resting on a bearing stratum $\left(E_{\mathrm{b}} / E_{\mathrm{s}}=10\right.$ and 100) with the effect of the degree of nonlinear non-homogeneity, $\delta$. The effect of the stiffness of the bearing stratum, $E_{\mathrm{b}} / E_{\mathrm{s}}$, on the reduction of the settlement influence factor is also less for granular pile stiffness parameter, $K_{\mathrm{gp} 0}$, in the range of 10-30. This is due to the relatively lower values of stiffness of the longer granular pile in the upper region and the presence of bearing strata at great depth. The effect of non-homogeneity is more in the range of $K_{\mathrm{gp} 0}=30-200$. The settlement influence factors for $K_{\mathrm{gp} 0}=100, E_{\mathrm{b}} / E_{\mathrm{s}}=100$ and $\delta=0,1,2,3$ and 4 are $0.104,0.096,0.091,0.086$ and 0.083 , respectively. The percentage reductions in the settlement influence factors with respect to those of a homogeneous granular pile are 7.7, 12.5, 17.03 and 20.19, respectively. While for $E_{\mathrm{b}} / E_{\mathrm{s}}=10$ and $\delta=0,1,2,3$ and 4, the settlement influence factors are $0.113,0.108,0.103,0.099$ and 0.097 , respectively. The percentage reductions in the settlement influence factors with respect to those of a homogeneous granular pile are $4.2,8.8,12.4$ and 14.15 , respectively. It can be said that the settlement reduction increases with increase in relative stiffness of the bearing stratum.

Figure 9 depicts the variation of the settlement influence factor $I_{\mathrm{sp}}$ with the relative stiffness parameter, $K_{\mathrm{gp} 0}$, for a longer granular pile $(L / d=20, \alpha=2)$ resting on a bearing stratum $\left(E_{\mathrm{b}} / E_{\mathrm{s}}=10\right.$ and 100) with the effect of the degree of non-linear non-homogeneity, $\delta$. Percentage reduction in the settlement influence factor, $I_{\mathrm{sp}}(\alpha=2)$, is less in comparison to that for the linear non-homogeneity parameter $\alpha=0$. For $E_{\mathrm{b}} / E_{\mathrm{s}}=100$, percentage reduction in

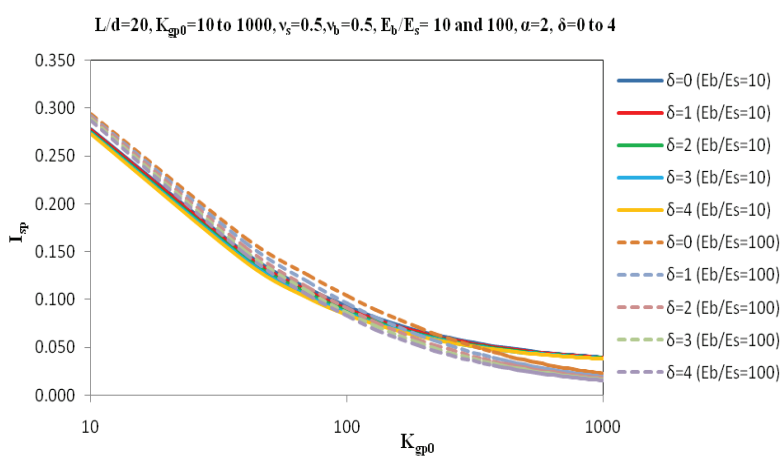

Figure 9: Variation of the settlement influence factor $l_{\text {sp, }}$ with the relative stiffness, $K_{\mathrm{gp} 0}$ : effect of the non-linear non-homogeneity parameter, $\delta\left(\alpha=2, L / d=20, E_{\mathrm{b}} / E_{\mathrm{s}}=10\right.$ and 100$)$.

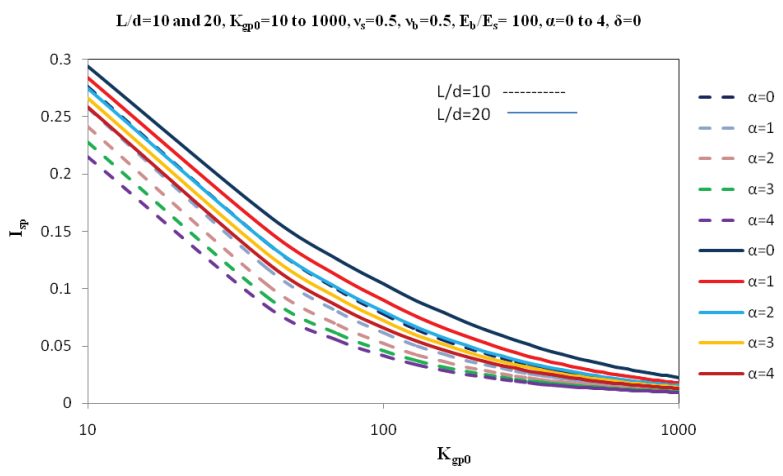

Figure 10: Variation of the settlement influence factor $l_{\mathrm{sp}}$ with the relative stiffness, $K_{\mathrm{gp} 0}$, for end-bearing granular pile: effect of linear non-homogeneity parameter, $\alpha$.

the settlement influence factor is more in comparison to that for $E_{\mathrm{b}} / E_{\mathrm{s}}=10$.

Variation of the settlement influence factor $I_{\mathrm{sp}}$ with the relative stiffness, $K_{\mathrm{gp} 0}$, of the granular pile with the effect of the linear non-homogeneity parameter, $\alpha$, is shown in Fig. 10. The effect of the degree of non-homogeneity of granular pile is pronounced for relative stiffness $K_{\mathrm{gp} 0}$ in the range of 10-200, and the settlement influence factor decreases with increase in values of $K_{\mathrm{gp} 0}$. For a relatively longer pile, the reduction in the settlement influence factor decreases in the $K_{\mathrm{gp} 0}$ range of 10-200, in comparison to that for a shorter pile.

The effect of the relative length $(L / d)$ of the granular pile and the relative stiffness of the bearing stratum $\left(E_{\mathrm{b}} /\right.$ $\left.E_{s}\right)$ on the settlement influence factor $\left(I_{\text {sp }}\right)$ with linear non-homogeneity parameter $(\alpha)$ is presented in Fig. 11 for $K_{\mathrm{gp} 0}=50$. The rate of decrease of the settlement influence factor with $\alpha$ is more for relatively shorter granular piles $(L / d=10$ and 20). In the case of longer granular pile with $L / d=40$, the effect of non-homogeneity on the settlement 
influence factor is negligible: due to the presence of the bearing strata at great depth, very less load is transferred to the lower reaches of the long homogeneous $(\alpha=0)$ compressible granular pile. The same phenomenon had been reported by Mattes and Poulos [1] and Scott [16]. Consequently, even if the modulus of deformation of the granular pile is higher $(\alpha>0)$ due to non-homogeneity, its effect on reduction in settlement would be very little. For the same reason, settlements of long granular piles $(L / d=$ 40) on a bearing stratum are little affected by the relative stiffness of the bearing stratum. The values of $I_{\mathrm{sp}}$ for $L / d$ $=40$ are nearly the same for $E_{\mathrm{b}} / E_{\mathrm{s}}=50$ and 1000 . The effect of the relative stiffness of the bearing stratum on the settlement influence factor is more for a shorter granular pile and increases with increase in the degree of the nonhomogeneity parameter, $\alpha$.

Figure 12 shows the variation of the settlement influence factor with the linear non-homogeneity parameter, $\alpha$, with the effect of the relative length $(L / d)$ of granular pile. The settlement influence factor decreases with increase in the linear non-homogeneity parameter for all values of relative length. For a shorter pile $(L / d$ $=10$ ), the rate of decrease of the settlement influence factor is more in comparison to that for a longer pile $(L / d$ $=40$ ). Furthermore, with increase in the non-linear nonhomogeneity parameter $\delta=0-2$, the percentage reduction of the settlement influence factor increases.

Variation of the settlement influence factor, $I_{\mathrm{sp}}$, with the linear non-homogeneity parameter, $\alpha$, for the relative length of the pile, with the effect of the relative stiffness of granular pile, is shown in Fig. 13. With increase in the non-linear non-homogeneity parameter, $\delta(0-2)$, the rate of decrease of the settlement influence factor increases. For a short pile, i.e. $L / d=10$, the rate of decrease of the settlement is more in comparison to that for a longer pile $(L / d=20)$.

Figure 14 shows the variation of the settlement influence factor, $I_{\mathrm{sp}}$, with non-linear non-homogeneity parameter, $\delta$, for a relative length of pile, with the effect of the relative stiffness of the granular pile. With increase in the non-linear non-homogeneity parameter, $\delta$, the settlement influence factor decreases. The rate of decrease of the settlement influence factor is greater for a shorter pile. With further increase in the linear non-homogeneity parameter, $\alpha$, from zero to two, the rate of decrease of the settlement influence factor increases more in comparison to that for a homogeneous granular pile with linear variation of the deformation modulus.

Figure 15 shows the variation of the settlement influence factor, $I_{\mathrm{sp}}$, with non-linear non-homogeneity parameter, $\delta$, for a relative length of the pile, with the effect

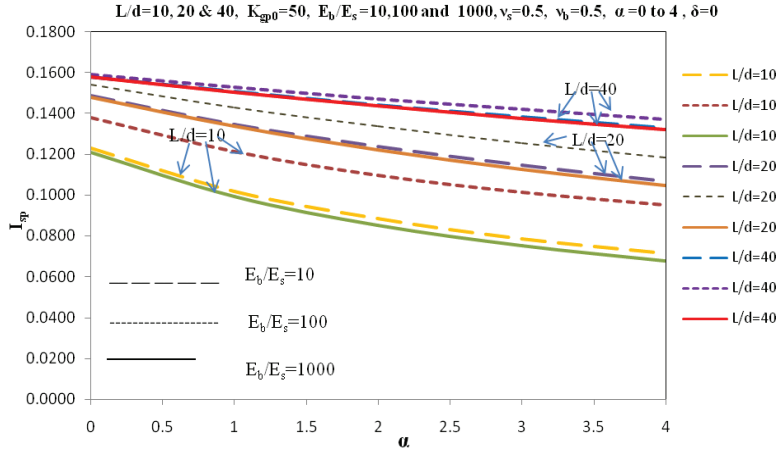

Figure 11: Variation of the settlement influence factor $I_{\mathrm{sp}}$, with the non-homogeneity parameter, $\alpha$, for end-bearing granular pile: effect of the relative stiffness of the bearing stratum $\left(E_{\mathrm{b}} / E_{\mathrm{s}}\right)$.

$\mathrm{L} / \mathrm{d}=10$ to $40, \mathrm{~K}_{\mathrm{qp} 0}=50, \mathrm{v}_{\mathrm{s}}=0.5, \mathrm{v}_{\mathrm{b}}=0.5, \mathrm{E}_{\mathrm{b}} / \mathrm{E}_{\mathrm{s}}=100, \alpha=0$ to $4, \delta=0$ and 2

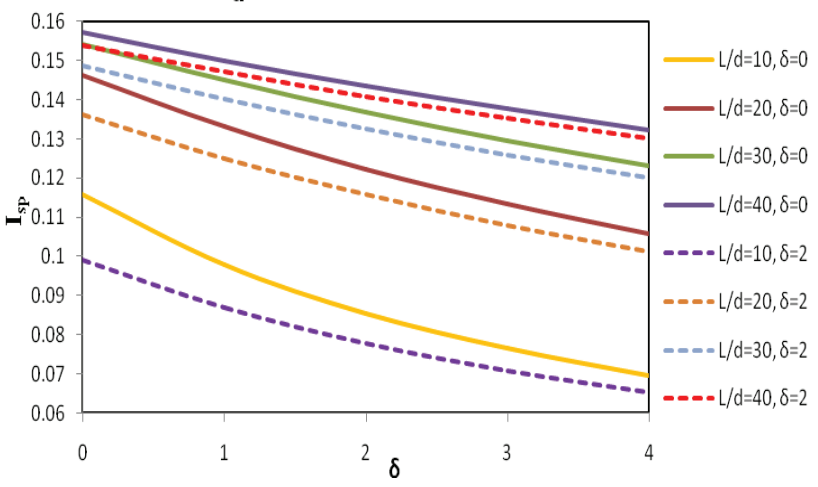

Figure 12: Variation of the settlement influence factor, $l_{\mathrm{sp}}$, with the linear non-homogeneity parameter, $\alpha$, for end-bearing granular pile: effect of $L / d(\delta=0$ and 2$)$.

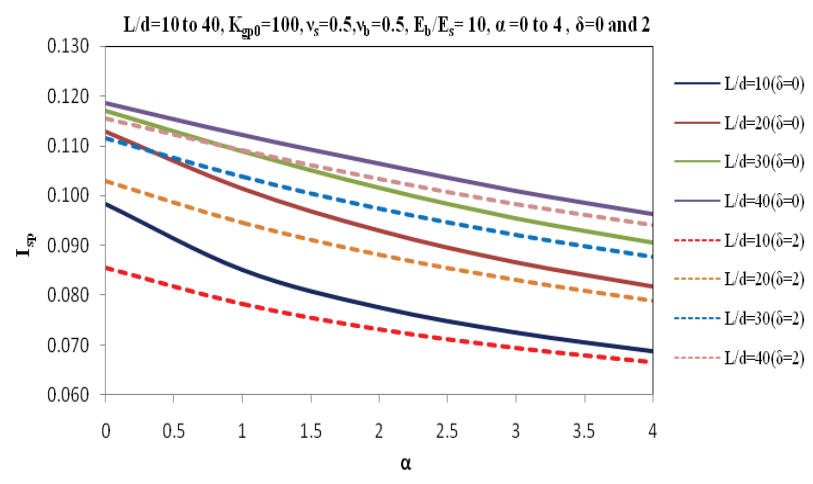

Figure 13: Variation of the settlement influence factor, $l_{\mathrm{sp}}$, with the linear non-homogeneity parameter, $\alpha$, for end-bearing granular pile: effect of $L / d\left(E_{\mathrm{b}} / E_{\mathrm{s}}=10, K_{\mathrm{gp} 0}=100\right)$.

of the relative stiffness of the granular pile. With increase in the non-homogeneity parameter, $\delta$, the settlement influence factor decreases. Furthermore, with increase in the linear non-homogeneity parameter, $\alpha$, from zero to two, the settlement influence factor decreases. 
$\mathrm{L} / \mathrm{d}=10$ to $40, \mathrm{~K}_{\mathrm{g}, 0}=100, \mathrm{v}_{\mathrm{s}}=0.5, \mathrm{r}_{\mathrm{b}}=0.5, \mathrm{E}_{\mathrm{b}} / \mathrm{E}_{\mathrm{s}}=100, \alpha=0$ and $2, \delta=0$ to 4

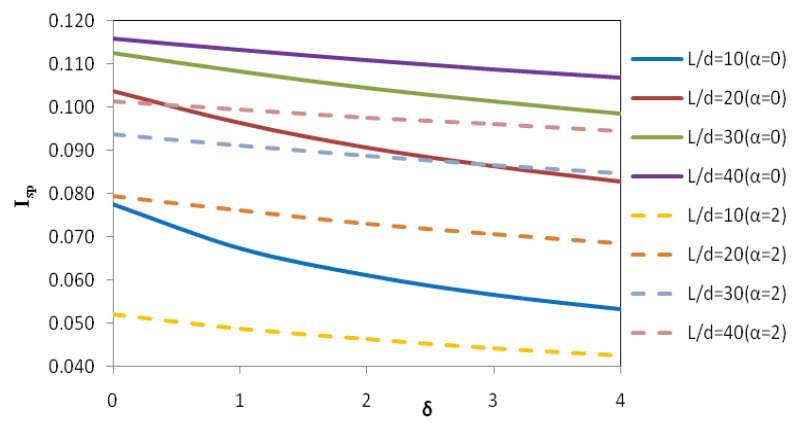

Figure 14: Variation of the settlement influence factor $l_{\mathrm{sp}}$ with the non-linear non-homogeneity parameter, $\delta$, for end-bearing granular pile: effect of relative length, $L / d\left(E_{\mathrm{b}} / E_{\mathrm{s}}=100\right)$.

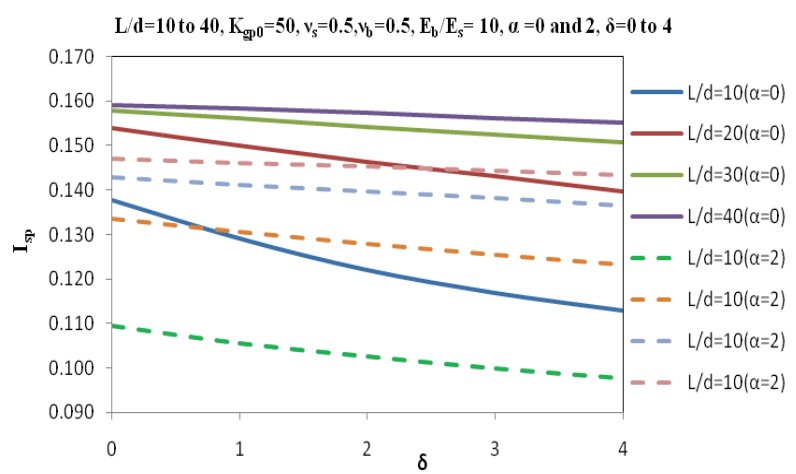

Figure 15: Variation of the settlement influence factor $I_{\mathrm{sp}}$ with the non-linear non-homogeneity parameter, $\delta$, for end-bearing granular pile: effect of $L / d\left(K_{\mathrm{gp} 0}=50, E_{\mathrm{b}} / E_{\mathrm{s}}=100\right)$.

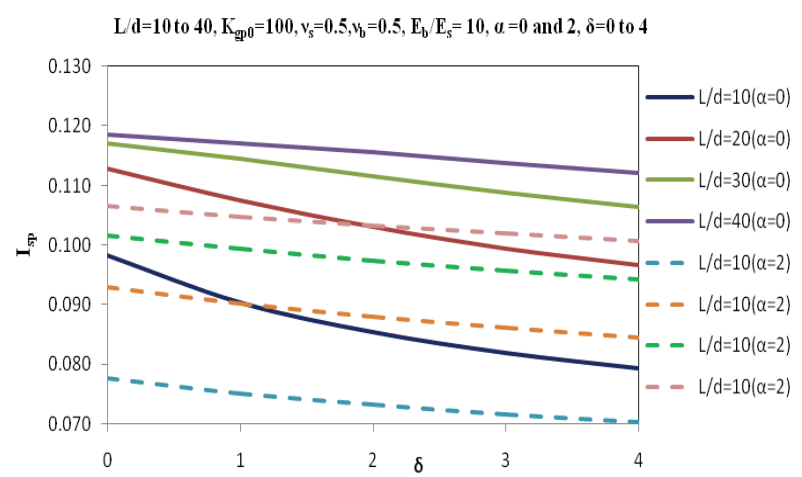

Figure 16: Variation of settlement influence factor $l_{\mathrm{sp}}$ with non-linear non-homogeneity parameter, $\delta$, for end-bearing granular pile: effect of $L / d\left(K_{\mathrm{gp} 0}=100, E_{\mathrm{b}} / E_{\mathrm{s}}=10\right)$.

Figure 16 shows the variation of the settlement influence factor, $I_{\mathrm{sp}}$, with the non-linear non-homogeneity parameter, $\delta$, for the relative length of a pile, with the effect of the relative stiffness of granular pile. With increase in non-homogeneity parameter, $\delta$, the settlement influence factor decreases. Furthermore, with increase

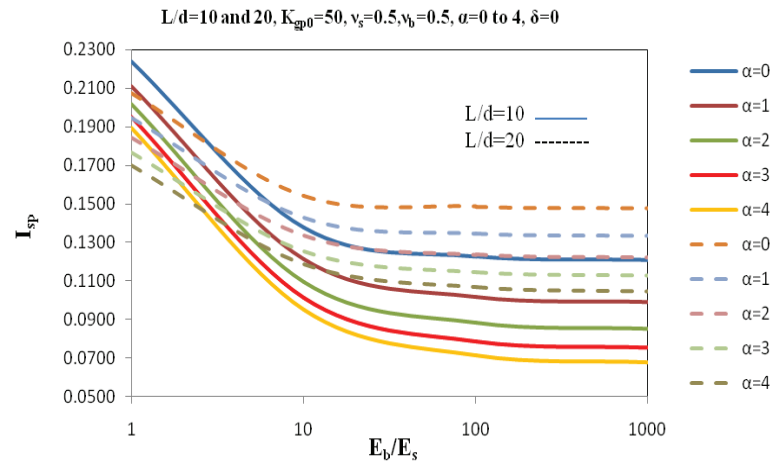

Figure 17: Variation of the settlement influence factor with relative stiffness of bearing stratum $\left(K_{\mathrm{gp} 0}=50\right)$.

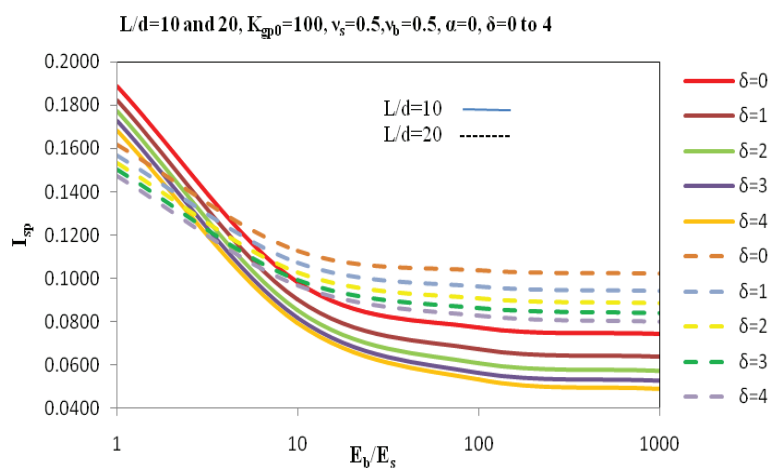

Figure 18: Variation of the settlement influence factor with relative stiffness of bearing stratum $\left(K_{\mathrm{gp} 0}=100\right)$.

in the linear non-homogeneity parameter, $\alpha$ from zero to two, the settlement influence factor decreases. With further increase in relative stiffness $K_{\mathrm{gp} 0}=50$ (Fig. 15) to 100 (Fig. 16), the rate of decrease of settlement influence factor decreases.

The variation of the settlement influence factor $\left(I_{\mathrm{sp}}\right)$ with the relative stiffness of the bearing stratum $\left(E_{\mathrm{b}} / E_{\mathrm{s}}\right)$ is presented in Fig. 17 for $L / d=10$ and 20, $K_{\text {gp } 0}=50$ and for different values of the linear non-homogeneity parameter, $\alpha$. The settlement influence factor decreases with increase of both parameters, i.e. relative stiffness of the bearing stratum and the degree of non-homogeneity, $\delta$. The settlement reduction is greater for a shorter granular pile.

Figure 18 shows the variation of the settlement influence factor $\left(I_{\mathrm{sp}}\right)$ with relative stiffness of the bearing stratum $\left(E_{\mathrm{b}} / E_{\mathrm{s}}\right)$ for $L / d=10$ and $L / d=20, K_{\mathrm{gp} 0}=100$ and different values of the non-linear non-homogeneity parameter, $\delta$. The settlement influence factor decreases with increase in relative stiffness of bearing stratum for both $L / d=10$ and 20. For the relative stiffness of the bearing stratum $\left(E_{\mathrm{b}} / E_{\mathrm{s}}\right)$ in the range of $10-1000$, the rate of 
decrease of the settlement influence factor $\left(I_{\mathrm{sp}}\right)$ decreases for relative length $L / d=20$, in comparison to that for $L / d$ $=10$. The effect of non-homogeneity of the granular pile, $\delta$, on settlement reductions is greater for a shorter granular pile.

The variation of the settlement influence factor $\left(I_{\mathrm{sp}}\right)$ with the relative stiffness of bearing stratum $\left(E_{b} / E_{s}\right)$ is presented in Fig. 19 for $L / d=10$ and $L / d=20, K_{\mathrm{gp} 0}=100$ and different values of the non-linear non-homogeneity parameter, $\delta$. The settlement influence factor decreases with increase of both parameters, i.e. relative stiffness of bearing stratum and the degree of non-homogeneity, $\delta$. The effect of non-homogeneity in the reduction of the settlement influence factor is significant at higher values of relative stiffness of the bearing stratum $\left(E_{\mathrm{b}} / E_{\mathrm{s}}=100\right.$ or 1000). The settlement influence factors for $E_{\mathrm{b}} / E_{\mathrm{s}}=10$ and $\alpha=0$ at $\delta=0$ and $\delta=2$ are approximately 0.0776 and 0.0732 for $L / d=10$. For $L / d=20$ and $\alpha=2$, the settlement influence factors are 0.0929 and 0.088 for $\delta=0$ and $\delta=2$, respectively. For all values of relative stiffness of the bearing stratum, the effect of the non-homogeneity of the granular pile on the settlement reductions of granular pile is greater for a shorter granular pile. Figure 19 also shows that with increase in the linear non-homogeneity parameter, i.e. from $\alpha=0$ to $\alpha=2$, the rate of decrease of the settlement influence factor is greater for the relative length $L / d=10$ and 20.

Variation of normalised shear stress $\tau^{\star}[=\tau /(\mathrm{P} / \pi \mathrm{dL})]$ with the normalised depth $z^{*}(=z / L)$ can be seen in Fig. 20 for $L / d=10$ and $K_{\mathrm{gp} 0}=50$, also showing the effect of the linear non-homogeneity parameter, $\alpha$, for a granular pile resting on a stiff bearing stratum $\left(E_{\mathrm{b}} / E_{\mathrm{s}}=10\right.$ and 1000). Shear stress at the soil-granular pile interface reduces in the upper compressible portion of the granular pile and increases in the lower stiffer portion of granular pile due to the non-homogeneity of the end-bearing granular pile. Beyond the normalised depth of about $z^{*}=0.85$, shear stresses increase slightly for the linear non-homogeneity parameter, $\alpha=2,3$ and 4 and $E_{\mathrm{b}} / E_{\mathrm{s}}=10$, due to transfer of load from the upper region to the lower stiffer region. Shear stresses at these depths are negative for $E_{\mathrm{b}} / E_{\mathrm{s}}=1000$, due to the relatively greater settling of the soil surrounding the granular pile compared with the deformation of the granular pile, i.e. an effect similar to a downdrag effect. From the pattern of shear stresses, it can be concluded that due to non-homogeneity of the granular pile, larger loads are transferred to the base, resulting in a reduction of the interfacial shear stresses over a significant length of the granular pile. The effect of non-homogeneity in reducing the interface shear stresses is more for the linear non-homogeneity parameter, $\alpha$, increasing from zero to

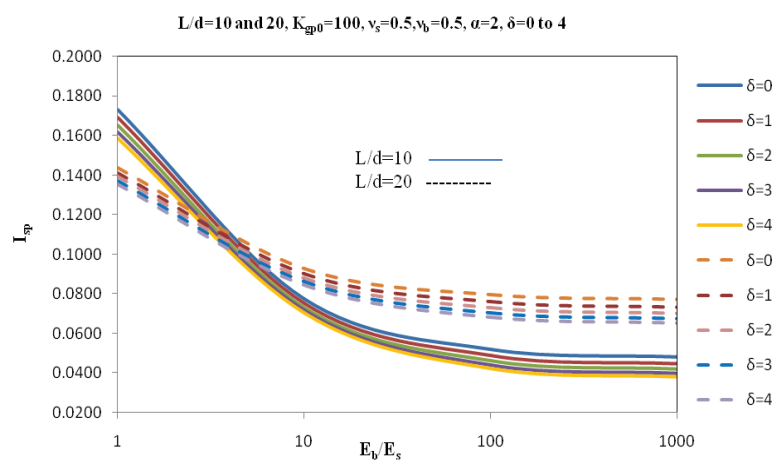

Figure 19: Variation of the settlement influence factor, $I_{s p}$ with relative stiffness, $E_{\mathrm{b}} / E_{\mathrm{s}}$, of the bearing stratum $(\alpha=2)$.

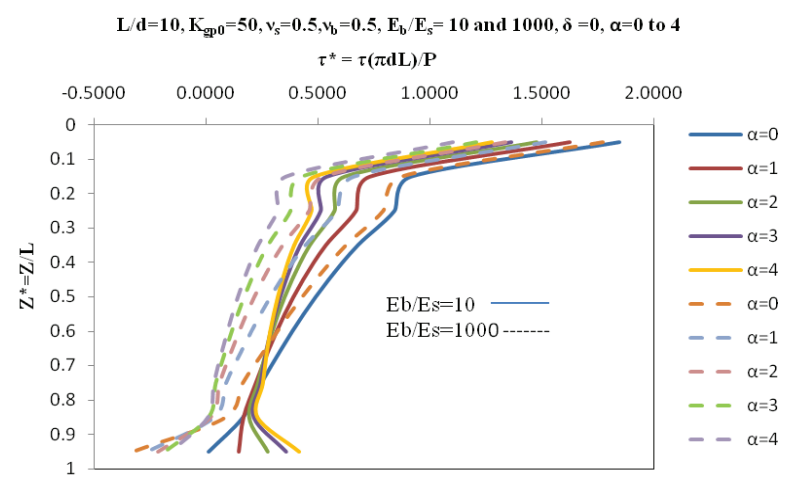

Figure 20: Variation of shear stress with depth with effect of linear non-homogeneity parameter, $\alpha(L / d=10)$

one in comparison to the effect due to $\alpha$ increasing from one to two or from two to four.

The influence of the non-homogeneity parameter $(\alpha)$ and the relative stiffness of the bearing stratum $\left(E_{b} /\right.$ $E_{\mathrm{s}}$ ) on the distribution of normalised shear stresses with normalised depth is presented in Fig. 21 for $L / d=20$ and $K_{\mathrm{gp0}}=50$. Results are shown for homogeneous $(\alpha=0)$ and non-homogeneous granular pile ( $\alpha=2,3$ and 4$)$, for soft $\left(E_{\mathrm{b}} / E_{\mathrm{s}}=10\right)$ and rigid $\left(E_{\mathrm{b}} / E_{\mathrm{s}}=1000\right)$ base conditions. It can be observed that non-homogeneity in deformation modulus causes a reduction in the shear stresses in the top half and an increase of the stresses in the lower half of the granular pile. The neutral point, i. e. the depth above which shear stresses become reduced and below which they increase, moves down with increasing stiffness of the bearing stratum. For granular pile resting on a relatively $\operatorname{stiff}\left(E_{\mathrm{b}} / E_{\mathrm{s}}=100\right)$ bearing stratum $\alpha=0$ and 2, the reduction in shear stresses is greater for $L / d=20$ than for $L / d=10$.

The variation of normalised shear stress $\tau^{\star}=\tau(\pi \mathrm{dL}) / P$ with normalised depth $Z^{\star}(=\mathrm{Z} / \mathrm{L})$ is presented in Fig. 22 and Fig. 23 for $L / d=10$ and 20, respectively, for $K_{\mathrm{gp}}=50$ with the effect of the degree of linear non-homogeneity, $\alpha(\delta=2)$, of a granular pile. With the increase in the degree 


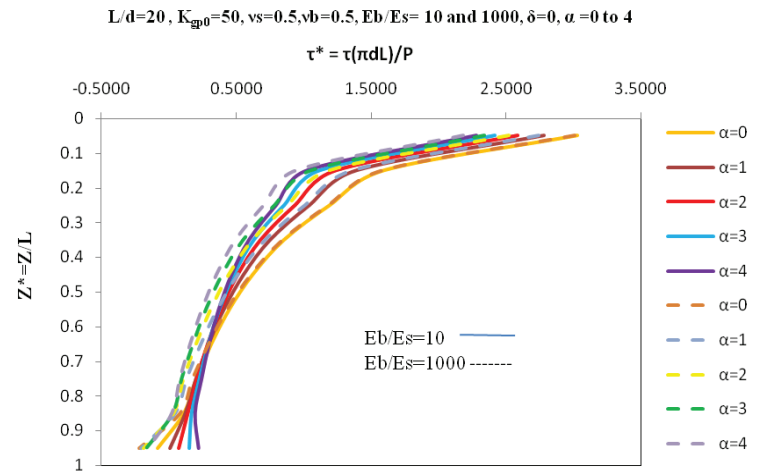

Figure 21: Variation of shear stress with depth with effect of linear non-homogeneity parameter, $\alpha(L / d=20)$.

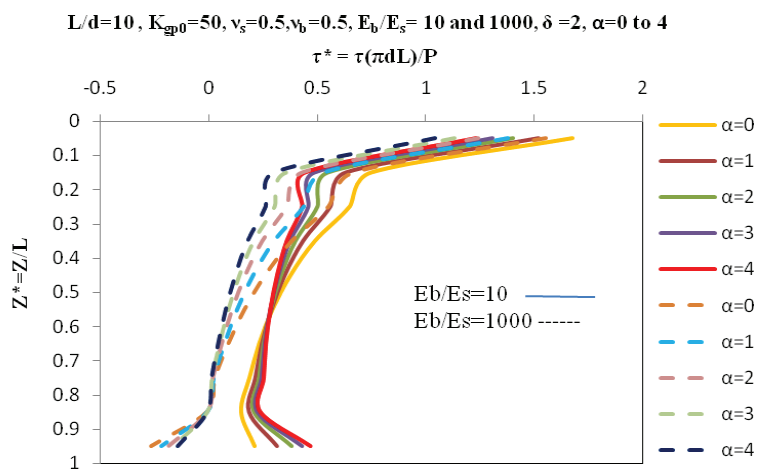

Figure 22: Variation of shear stress with depth with effect of linear non-homogeneity parameter, $\alpha(\delta=2)$.

of non-linear non-homogeneity, $\delta=2$ of the granular pile, the shear stress decreases with depth in the upper portion of the granular pile approximately over half of its length and increases in the lower half of the granular pile. With increase in relative stiffness of the bearing stratum $E_{\mathrm{b}} / E_{\mathrm{s}}$ $=10$ to 1000 , the shear stresses decrease.

Distribution of normalised axial load, $P_{z}^{\star}\left(=P_{z} / P\right)$, with normalised depth $z^{*}(=z / L)$ of a granular pile resting on a stiff bearing stratum $\left(E_{\mathrm{b}} / E_{\mathrm{s}}=100\right)$ is shown in Fig. 24 for $L / d=10$ and $20, K_{\mathrm{gp} 0}=50$, along with the influence of linear non-homogeneity parameter, $\delta$. The normalised axial load of the granular pile decreases with normalised depth due to transfer of load through interfacial shear stresses. The normalised axial load of granular pile increases with the increase in the degree of non-homogeneity of the granular pile due to reduction in the interfacial shear stresses, as shown in Fig. 24. Interestingly, the normalised load of granular pile increases for $z>0.85 L$ due to the psuedodowndrag effect in that region of the granular pile, as shown in Fig. 23. The values of $P_{z}^{*}$ at the normalised depth

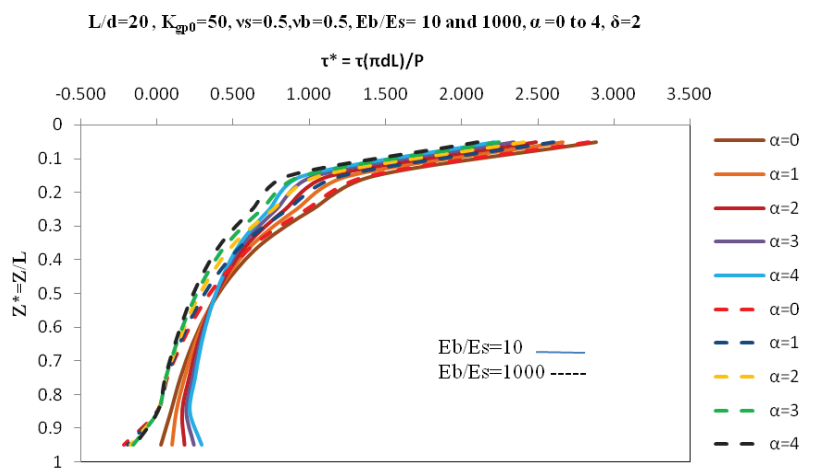

Figure 23: Variation of shear stress with depth with effect of linear non-homogeneity parameter, $\alpha(L / d=20)$.

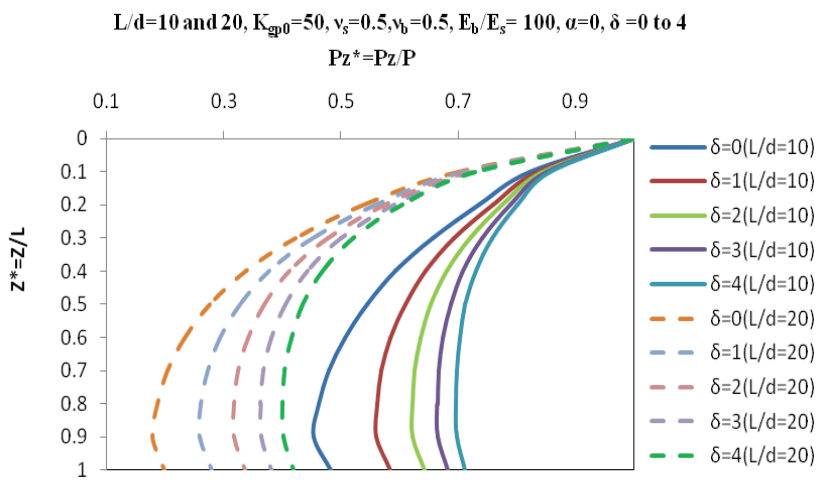

Figure 24: Variation of normalised axial load, $P_{z}^{*}\left(=P_{z} / P\right)$, with normalised depth $z^{*}(=z / L)$ : effect of non-linear non-homogeneity parameter, $\delta(\alpha=0)$.

of $z^{*}=0.6$ are $0.506,0.584,0.636$ and 0.702 for $\delta=0,1,2$ and 4, respectively.

Distribution of normalised axial load, $P_{z}^{*}\left(=P_{z} / P\right)$ with normalised depth $z^{*}(=z / L)$ of a granular pile resting on a stiff bearing stratum $\left(E_{\mathrm{b}} / E_{\mathrm{s}}=100\right)$ is shown in Fig. 25 for $L / d=10$ and 20 and $K_{\mathrm{gp} 0}=50$, along with the influence of the non-homogeneity parameter, $\alpha$. The normalised load of the granular pile reduces with depth due to transfer of load through interfacial shear stresses. The normalised load in the granular pile increases slightly for $z>0.9 \mathrm{~L}$ due to the negative shear stresses along the granular pile-soil interface near the region of the stiff bearing stratum. With the increase in the degree of linear non-homogeneity of the granular pile, the normalised load along the granular pile increases at all depths and becomes uniform due to reduction in interfacial shear stresses, as seen in Fig. 25. The non-homogeneity of the granular pile resting on a stiff bearing stratum increases the transfer of load to the base significantly. 


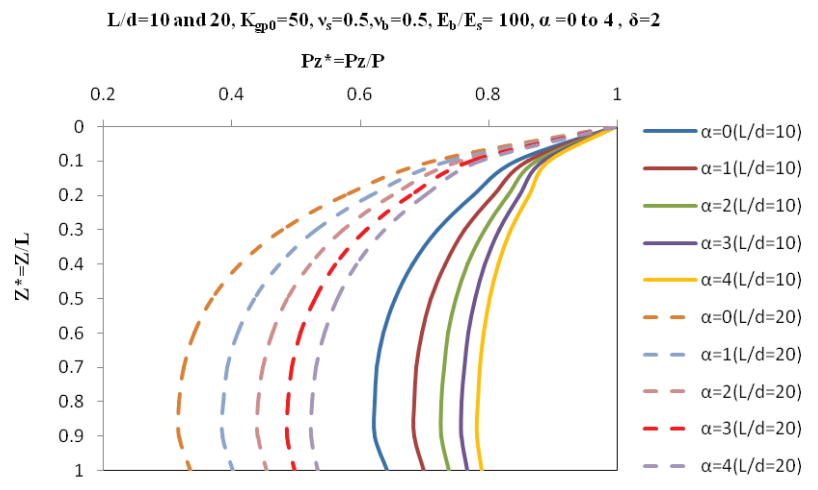

Figure 25: Variation of normalised axial load, $P_{z}^{*}\left(=P_{z} / P\right)$, with normalised depth $z^{*}(=z / L)$ : effect of non-linear non-homogeneity parameter, $\alpha(\delta=2)$.

The variation of the percentage base load, $\left(P_{\mathrm{b}} / P\right) \times 100$, with the relative stiffness parameter, $K_{\mathrm{gp} 0}$, can be seen in Fig. $26\left(E_{\mathrm{b}} / E_{\mathrm{s}}=10\right)$ for different relative lengths $L / d$ of the granular pile. The percentage base load increases with the non-homogeneity parameter due to the transfer of more loads from the top region of the granular pile to the base. The base load is larger for a short granular pile, due to the presence of the stiff bearing stratum at a shallower depth.

The variation of the percentage base load, $\left(P_{\mathrm{b}} / P\right) \times 100$, with the relative stiffness parameter, $K_{\mathrm{gp} 0}$, can be seen in Fig. 27, with $E_{\mathrm{b}} / E_{\mathrm{s}}=10$ for different relative lengths $L / d$ of the granular pile. The percentage base load increases with the non-homogeneity parameter due to the transfer of greater load from the top region of the granular pile to the base. The base load is larger for a short granular pile, due to the presence of a stiff bearing stratum at a shallower depth. In the case of a short granular pile $(L / d$ $=10$ ), the rate of increase of the base load with $\alpha$ is less due to the higher load transferred to the base even for a homogeneous granular pile $(\alpha=0)$. For a long granular pile $(L / d=20)$, this rate is also less due to the presence of the bearing stratum at great depth. The percentage base loads for $L / d=10, \delta=0$ and $K_{\mathrm{gp} 0}=100$ for $\alpha=0$ and 4 are 50.95 and 60.34 , respectively, while for $L / d=20$, the corresponding values are 27.5 and 42.3, respectively. Similarly the percentage base loads for $L / d=10, \delta=2$ and $K_{\mathrm{gp0}}=100$ for $\alpha=0$ and 4 are 56.53 and 61.15, respectively, while for $L / d=20$, the corresponding values are 35.93 and 43.81, respectively. It is also observed that at $L / d=10$ and 20 for higher values of $K_{\mathrm{gp} p}$, i.e. in the range of 600-1000, the percentage base load is almost the same for $\alpha=1,2,3$ and 4.

Fig. 28 shows the variation of percentage base load, $\left(P_{\mathrm{b}} / P\right) \times 100$, with relative stiffness of the bearing stratum, $E_{\mathrm{b}} / E_{\mathrm{s}}$, for different values of the non-homogeneity

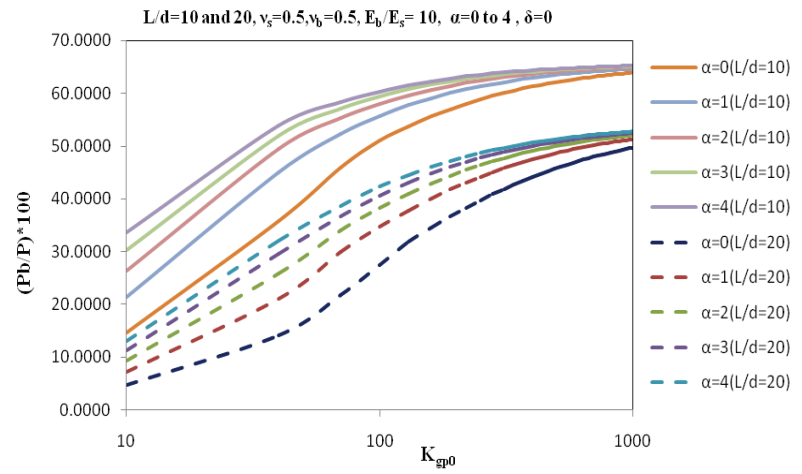

Figure 26: Variation of the percentage base load, $\left(P_{\mathrm{b}} / P\right) \times 100$, with the relative stiffness parameter, $K_{\mathrm{gp} 0}$ : effect of the linear nonhomogeneity parameter, $\alpha\left(E_{\mathrm{b}} / E_{\mathrm{s}}=10, \delta=0\right)$.

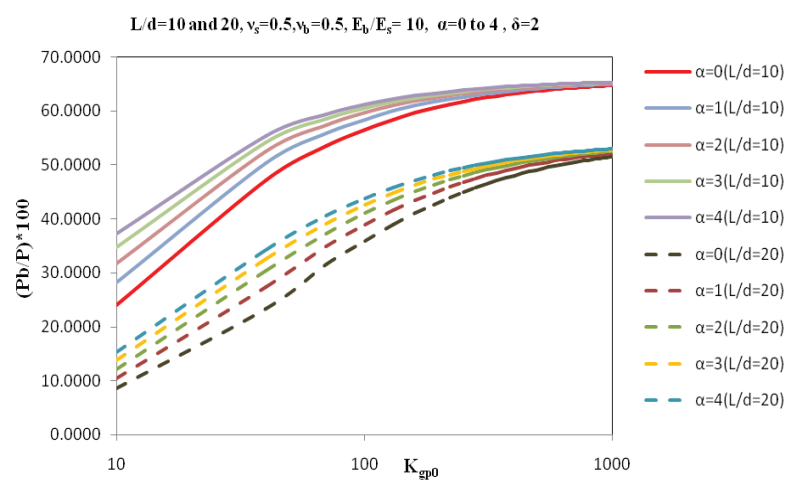

Figure 27: Variation of the percentage base load, $\left(P_{\mathrm{b}} / P\right) \times 100$, with the relative stiffness parameter, $K_{\mathrm{gp} 0}$ : effect of the linear nonhomogeneity parameter, $\alpha(\delta=2)$.

parameter $(\delta)$ and relative length of the granular pile $(L / d)$ for $K_{\mathrm{gp} 0}=100$. The base load increases both with relative stiffness of the bearing stratum $\left(E_{\mathrm{b}} / E_{\mathrm{s}}\right)$ and with the non-linear non-homogeneity parameter $\delta$. For a floating granular pile $\left(E_{\mathrm{b}} / E_{\mathrm{s}}=1\right)$, the effect of the non-homogeneity of the granular pile on the base load is insignificant. The percentage increment in the base load for an increase in the non-linear non-homogeneity parameter, $\delta$, from zero to one is greater in comparison to the increase of $\delta$ from one to two for any relative length of the pile. In the case of a long granular pile, the percentage base load is less in comparison to the base load for a short granular pile. The effect of non-homogeneity of granular pile on the base load increases with the increase in the relative stiffness of the bearing stratum. For $E_{\mathrm{b}} / E_{\mathrm{s}}=1000$, the bearing stratum is almost rigid and the percentage base load becomes nearly constant with further increase in $E_{\mathrm{b}} / E_{\mathrm{s}}$.

Figure 29 shows the variation of the percentage base load, $\left(P_{\mathrm{b}} / P\right) \times 100$, with relative stiffness of the 


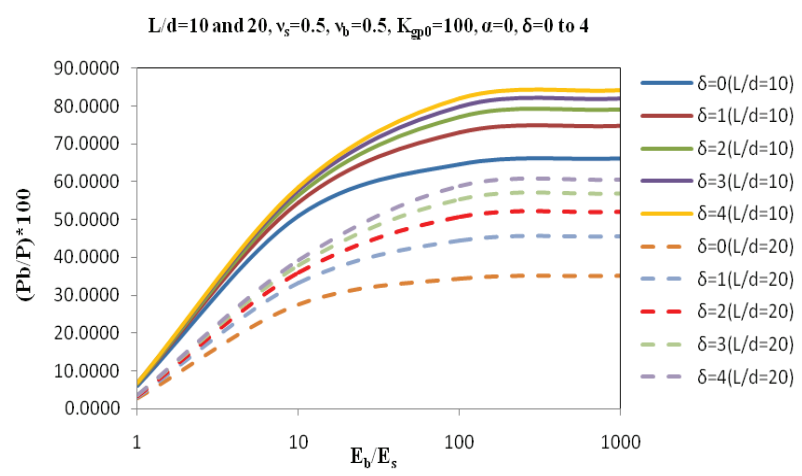

Figure 28: Variation of percentage base load, $\left(P_{\mathrm{b}} / P\right) \times 100$, with relative stiffness of the bearing stratum, $E_{b} / E_{s}$, for different values of the non-linear non-homogeneity parameter, $\delta(\alpha=0)$.

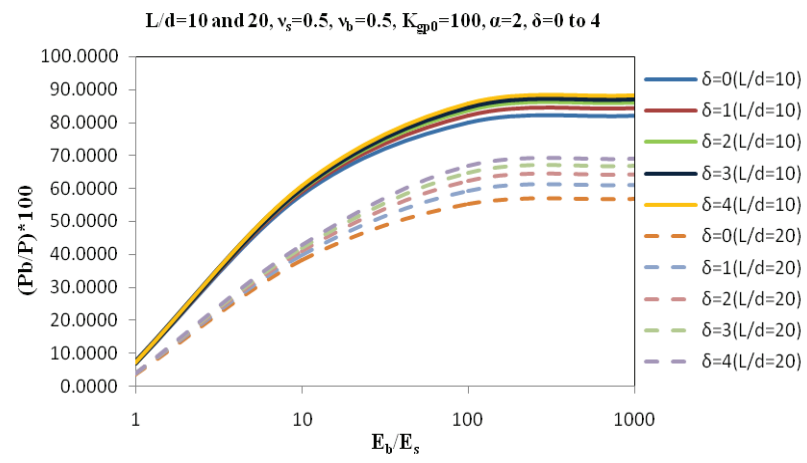

Figure 29: Variation of percentage base load, $\left(P_{\mathrm{b}} / P\right) \times 100$, with relative stiffness of the bearing stratum, $E_{\mathrm{b}} / E_{\mathrm{s}}$, for the non-linear non-homogeneity parameter, $\delta(\alpha=2)$.

bearing stratum, $E_{\mathrm{b}} / E_{\mathrm{s}}$, for different values of the nonhomogeneity parameter $(\delta)$ and relative lengths of the granular pile $(L / d)$ for $K_{\mathrm{gp} 0}=100$. The base load increases both with relative stiffness of the bearing stratum $\left(E_{b} / E_{s}\right)$ and the non-linear non-homogeneity parameter, $\delta$. With increase in the linear non-homogeneity, $\alpha=0-2$, of the granular pile, the rate of increase of the percentage base load is greater. For a longer granular pile, the percentage base load is less in comparison to the base load for a shorter granular pile. The effect of non-homogeneity of the granular pile on the base load increases with the increase in the relative stiffness of the bearing stratum. For $E_{\mathrm{b}} / E_{\mathrm{s}}=1000$, the bearing stratum is almost rigid, and the percentage base load becomes nearly constant with further increase in $E_{\mathrm{b}} / E_{\mathrm{s}}$.

\section{Conclusions}

The present analysis is based on the elastic continuum approach. The formulation of a new pile displacement matrix for the non-linear variation of the deformation modulus for an end-bearing granular pile is developed using the finite difference technique. The formulation for a floating granular pile displacement matrix for the non-linear variation of the deformation modulus has been developed previously, using the finite difference technique [5]. The non-homogeneity parameters $\alpha$ and $\delta$ are introduced, which represent the linear and non-linear non-homogeneities up to the power of twa degrees......

a) A new pile displacement matrix is developed for endbearing granular pile, incorporating the non-linear behaviour in terms of the deformation modulus. The present formulation is applicable to and can be extended for any degree of non-homogeneity.

b) Numerical solutions for the top displacement, normalised shear stress and load distributions with depth, as well as the percentage load transferred to the base, are obtained for a non-homogeneous endbearing granular pile in homogeneous soil conditions.

c) The reductions in settlement for end-bearing nonhomogenous granular pile are in the range of $20 \%-$ $40 \%$ with respect to the settlement of a homogeneous granular pile depending on the relative stiffness of the bearing stratum and the degree of the nonhomogeneities $\alpha$ and $\delta$ of the end-bearing granular pile.

d) The settlement influence factor decreases with increase in the linear and non-linear non-homogeneity parameters $\alpha$ and $\delta$ for all values of relative length. For a shorter pile, the rate of decrease of the settlement influence factor is greater in comparison to that for a longer pile due to the presence of the bearing stratum at a shallow depth.

e) The shear stresses in the top $85 \%$ of the length of the granular pile decrease with increase of the nonlinear non-homogeneity parameter, $\delta$. In the region near the bearing stratum of the end-bearing granular pile, the shear stresses obtained are negative, i.e. an effect similar to downdrag. This is due to the major load transferred to the base. In order to achieve compatibility of the displacements of the nodes for both the soil and the granular pile near the bearing stratum, shear stresses become negative.

f) The axial load distribution with depth increases with the non-homogeneity parameters $\alpha$ and $\delta$ due to reduction in the interfacial shear stresses. The reductions in interfacial shear stresses are mainly due 
to the transfer of a major part of the shaft stresses to the bearing stratum.

g) The percentage of load transferred to the pile base increases with the increase of the degree of nonhomogeneity of the granular pile.

Acknowledgement: Gupta is privileged to express her sincere gratitude to Prof. J.K. Sharma (Civil Engineering Department, Rajasthan Technical University, Kota, Rajasthan) for his contribution to the present work. His high appreciation and positive attitude have played an important role in the outcome of this research work.

\section{References}

[1] Mattes, N.S., Poulos, H.G. (1969). Settlement of single compressible pile. Journal of the Soil Mechanics and Foundations Division, ASCE, 95(SM1), 189-207.

[2] Poulos, H.G., Mattes, N.S. (1969). The behavior of axiallyloaded end-bearing piles. Geotechnique, 19, 285-300.

[3] Butterfield, R., Banerjee, P.K. (1971). The elastic analysis of compressible piles and pile groups. Geotechnique, 21(1), 43-60.

[4] Madhav, M.R., Sharma, J.K., Chandra, S. (2006). Analysis and settlement of a non-homogeneous granular pile. Indian Geotechnical Journal, 36(3), 249-271.

[5] Gupta, P., Sharma, J.K. (2018). Settlement analysis of nonhomogeneous single granular pile. Indian Geotechnical Journal, 48(1), 92-101. doi: 10.1007/s40098-017-0240-z.

[6] Alamgir, M., Miura, N., Poorooshasb, H.B., Madhav, M.R. 1996. Deformation analysis of soft ground reinforced by columnar inclusions. Computers and Geotechnics, 18(4), 267-299.

[7] Madhav, M.R., Sharma, J.K., Sivakumar, V. (2009). Settlement and load distribution in a granular piled raft. Geomechanics and Engineering, 1(1), 97-112.

[8] Zhang, L., Zhao, M., Shi, C., Zhao, H. (2013). Settlement calculation of composite foundation reinforced with stone columns. International Journal of Geo-mechanics, ASCE, 13(3), 248-256.

[9] Indraratna, B., Basack, S., Rujikiatkamjorn, C. (2013). Numerical solution of stone column improved soft soil considering arching, clogging and smear effects. Journal of Geotechnical and Geoenvironmental Engineering, 139(3), 377394.

[10] Randolph, M.F., Wroth, C.P. (1978). Analysis of deformation of vertically loaded piles. Journal of the Geotechnical Engineering Division, ASCE 104(GT2), 1465-1488.

[11] Eldho, C.A., Jose, A., Balamurugan, V., Parackal, P.J., Priya, K.L. (2010). Ground improvement using stone columns and PVD. In: Indian Geotechnical Conference, December 16-18, 2010 GEOtrendz, IGS Mumbai Chapter \& IIT Bombay,Mumbai(India).

[12] Hayashi, H., Nishimoto, S., Takahashi, M. (2011). Field performance of PVD combined with reinforced embankment on peaty ground. Journal of Soils and Foundations, 51(1), 191-201.
[13] Cecilia, B., Serge, L. (2013). Case studies of stone columns improvement in seismic areas. In: 3ème CMIG' Alger, 18 et 19, Algeria.

[14] Andreou, P., Papadopoulos, V. (2014). Factors affecting the settlement estimation of stone column reinforced soils. Geotechnical and Geological Engineering, 32(5), 1175-1185.

[15] Etezad, M., Hanna, A.M., Ayadat, T. (2014). Bearing capacity of a group of stone columns in soft soil. International Journal of Geomechanics, 15(2), 04014043.

[16] Scott, R.F. (1981). Foundation Analysis. Prentice-Hall Inc., Englewood Cliffs, NJ, p. 545. 